\section{POS0491 LEFT VENTRICULAR GEOMETRIC ABNORMALITIES ASSOCIATED WITH HIGHER TITERS OF RHEUMATOID FACTOR AND ANTI-CYCLIC CITRULLINATED PEPTIDE ANTIBODIES IN RHEUMATOID ARTHRITIS PATIENTS}

N. Guajardo-Jauregui ${ }^{1}$, J. R. Azpiri-López ${ }^{2}$, D. Á. Galarza-Delgado ${ }^{1}$, I. J. Colunga-Pedraza ${ }^{1}$, S. Lugo-Perez ${ }^{2}$, A. B. Rodriguez-Romero ${ }^{1}$, A. Cárdenas ${ }^{1}$, O. A. Cepeda-Ayala ${ }^{2}$, H. Azpiri-Diaz ${ }^{2}{ }^{1}{ }^{H}$ Hospital Universitario "Dr. José Eleuterio González", Universidad Autónoma de Nuevo León, Rheumatology, Monterrey, Mexico; ${ }^{2}$ Hospital Universitario "Dr. José Eleuterio González", Universidad Autónoma de Nuevo León, Cardiology, Monterrey, Mexico

Background: Rheumatoid arthritis (RA) patients have a higher risk of developing left ventricular (LV) geometric abnormalities which can result in the development of heart failure and cardiac death (1). High titers of rheumatoid factor (RF) and anti-cyclic citrullinated peptide (anti-CCP) antibodies are associated with a worse cardiovascular (CV) prognosis in RA patients (2).

Objectives: The aim of this study was to assess the association between RF and anti-CCP antibody titers, and the LV geometric abnormalities detected by a transthoracic echocardiogram.

Methods: This was a cross-sectional, observational, and comparative study. Patients aged 40-75 years who fulfilled the 2010 ACR/EULAR classification criteria for RA underwent a transthoracic echocardiogram. Patients with RA and an alteration of LV geometry were matched to RA patients with normal LV geometry, by age, gender, comorbidities, and disease characteristics to eliminate confounders. LV geometry was evaluated with LV mass index and relative wall thickness. A blood sample was taken to measure RF and anti-CCP antibody titers. Distribution was evaluated with the Kolmogorov-Smirnov test. Comparisons were done with Chi square test for qualitative variables and Student's $t$ test and Mann-Whitney's $U$ test for quantitative variables. A $p$-value $<0.05$ was considered statistically significant.

Results: A total of 82 RA patients were included in this study, 41 patients with altered LV geometry and 41 patients with normal LV geometry. Of the 41 patients with LV geometric abnormalities, 37 (90.2\%) presented LV concentric remodeling and 4 $(9.8 \%)$ presented LV concentric hypertrophy. We found no significant differences in the demographic and clinical characteristics between both groups (Table 1). Patients with altered LV geometry showed higher titers of IgA-RF $(102.11 \mathrm{U} / \mathrm{ml} \mathrm{vs} 21.70 \mathrm{U} / \mathrm{ml}$, $p=0.011$ ) and anti-CCP antibodies (193.04U/ml vs $18.29 \mathrm{U} / \mathrm{ml}, p=0.005$ ) (Figure 1 ).

Table 1. Demographic and disease characteristics.

\begin{tabular}{|c|c|c|c|}
\hline & $\begin{array}{l}\text { RA patients with } \\
\text { altered LV geometry } \\
(\mathrm{n}=41)\end{array}$ & $\begin{array}{c}\text { RA patients } \\
\text { with normal LV } \\
\text { geometry } \\
(n=41)\end{array}$ & $p$ \\
\hline Age years, mean $\pm S D$ & $53.12 \pm 7.62$ & $52.34 \pm 7.74$ & NS \\
\hline Women, n (\%) & $39(95.1)$ & $39(95.1)$ & NS \\
\hline T2DM, n (\%) & $7(17.1)$ & $4(9.8)$ & NS \\
\hline HTN, $n(\%)$ & $13(31.7)$ & $10(24.4)$ & NS \\
\hline Dyslipidemia, n (\%) & 9 (22.0) & $11(26.8)$ & NS \\
\hline Active smoking, $\mathrm{n}(\%)$ & $4(9.8)$ & $3(7.3)$ & NS \\
\hline Obesity, $\mathrm{n}(\%)$ & $11(26.8)$ & $14(34.1)$ & NS \\
\hline $\mathrm{BMI} \mathrm{kg} / \mathrm{m}^{2}$, median (p25-p75) & $27.95(25.33-31.45)$ & $28.42(25.84-32.00)$ & NS \\
\hline $\begin{array}{l}\text { Disease duration years, } \\
\text { median (p25-p75) }\end{array}$ & $10.37(2.72-17.80)$ & $6.40(3.43-13.29)$ & NS \\
\hline CDAI, median (p25-p75) & $14.00(2.00-22.00)$ & $10.00(3.00-16.50)$ & NS \\
\hline DAS28-CRP, mean \pm SD & $3.52 \pm 1.42$ & $3.09 \pm 1.11$ & NS \\
\hline \multicolumn{4}{|l|}{ Treatment } \\
\hline MTX, n (\%) & $33(80.5)$ & 34 (82.9) & NS \\
\hline Glucocorticoids, n (\%) & $25(61.0)$ & $23(56.1)$ & NS \\
\hline Antihypertensive, n (\%) & $13(31.7)$ & $8(19.5)$ & NS \\
\hline Statins, n (\%) & $6(14.6)$ & $4(9.8)$ & NS \\
\hline
\end{tabular}

RA, rheumatoid arthritis; LV, left ventricular; NS, not significant; T2DM, type 2 diabetes mellitus; HTN, hypertension; BMI, body mass index; CDAl, clinical disease activity index; DAS28, disease activity score using 28 joints; CPR, C-reactive protein; MTX, methotrexate.

Conclusion: RA patients with altered LV geometry had higher titers of IgA-RF and anti-CCP antibodies. This suggests an association between antibody titers and $\mathrm{CV}$ prognosis in RA patients. Rheumatologists should take these data into account when evaluating CV risk in RA patients, assessing the possibility of performing an echocardiogram for early detection of $\mathrm{CV}$ abnormalities and an opportune treatment in this group of patients.

REFERENCES:

[1] Myasoedova E, Davis JM, 3rd, Crowson CS, et al. Brief report: rheumatoid arthritis is associated with left ventricular concentric remodeling: results of a population-based cross-sectional study. Arthritis Rheum 2013;65(7):1713-8. doi: 10.1002/art.37949

[2] Geraldino-Pardilla L, Russo C, Sokolove J, et al. Association of anti-citrullinated protein or peptide antibodies with left ventricular structure and function in rheumatoid arthritis. Rheumatology (Oxford) 2017;56(4):534-40. doi: 10.1093/rheumatology/kew436
Figure 1. Antibody titers.

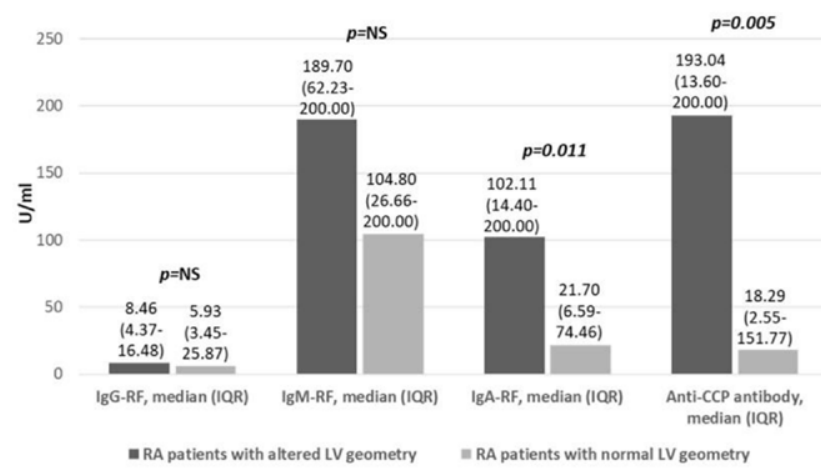

Acknowledgements: We have no acknowledgements to declare.

Disclosure of Interests: None declared

DOI: 10.1136/annrheumdis-2021-eular.3375

\section{POS0492 A MOLECULAR SIGNATURE RESPONSE CLASSIFIER PREDICTS THE LIKELIHOOD OF EULAR NON- RESPONSE TO TNF INHIBITOR THERAPIES IN RA: RESULTS FROM A RETROSPECTIVE COHORT ANALYSIS}

L. Zhang ${ }^{1}$, C. van der Tog $^{2}$, A. den Broeder ${ }^{2}$, T. Mellors $^{1}$, E. Connolly-Strong ${ }^{1}$, J. Withers ${ }^{1}$, A. Jones ${ }^{1}$, V. Akmaev ${ }^{1}{ }^{1}$ Scipher Medicine Corporation, Science and Technology, Waltham, United States of America; ${ }^{2}$ Sint Maartenskliniek, Department of Rheumatology, Ubbergen, Netherlands

Background: Following RA treatment recommendations, most people with rheumatoid arthritis (RA) begin targeted therapy with TNF inhibitors (TNFi), even though inadequate response to TNFi therapies is widespread. Treatment changes from one medication to the next are currently fueled by disease-activity measures and eventually result in disease control for most patients; however, this "trial-and-error" approach wastes precious time on ineffective treatments. A delay in reaching treat-to-target goals has a negative effect on patient burden and, possibly, disease progression. ${ }^{1}$ Useful predictors for TNFi response have been challenging to identify but a specific molecular signature response classifier (MSRC) test was shown to be predictive for inadequate response to TNFi therapies. ${ }^{2}$ The impact of such identification has the potential to result in improved patient outcomes, but further validation would be welcome, especially for response criteria other than ACR50, and in a stringent treat-to-target setting with lower baseline disease activity.

Objectives: To validate the predictive value of the MSRC test in identifying those patients who do not meet EULAR good response criteria after 6 months of TNFi treatment.

Methods: Data from a prospective cohort study conducted in the Sint Maartenskliniek (Nijmegen, the Netherlands) of RA patients who started adalimumab or etanercept TNFi as their first biologic were included. ${ }^{3}$ Baseline RNA samples and clinical assessments were used to identify patients who had a molecular signature $^{1}$ of non-response to TNFi therapy. Outcomes were calculated at six months using DAS28-CRP-based EULAR good response, and high and low confidence responders and non-responders were identified using Monte Carlo simulation with 2,000 repeats and $70 \%$ precision cut off. Outcome measurements were blinded for test results. Treatment switch before 6 months was imputed as non-response. Odds ratios and area under the ROC curve (AUC) assessments were used to evaluate the ability of the MSRC test to predict inadequate response at 6 months against EULAR good response criteria.

Results: A total of 68 out of 88 RA patients were identified to have a high-confidence response status and were included in analyses (Table 1). EULAR good response was observed in $45.5 \%(31 / 68)$ of patients. Patients were stratified according to detection of a molecular signature of non-response with an AUC of 0.61 . The odds that a patient with the molecular signature of non-response at baseline failed to achieve a EULAR good response at 6 months was four times greater than that of a patient lacking the molecular signature (odds ratio 4.0, $95 \%$ confidence interval 1.2-13.3).

Table 1. Patient demographics

Characteristic RA patients $(\mathrm{N}=68)$

Age, median (SD)

Female, n (\%)

57 (11)

CCP positive, $\mathrm{n}(\%)$

$43(63.2)$

RF positive, $n(\%)$

$34(50.0)$

Prescribed adalimumab at baseline, $n(\%)$

38 (55.9)

Prescribed adalimumab at baseline, $\mathrm{n}(\%)$
Prescribed etanercept at baseline, $\mathrm{n}(\%)$ 57 (83.8) 
Conclusion: In this validation study, the molecular signature of non-response identified patients who did not fulfill the EULAR good response criteria to TNFi therapies. The patient selection process for this study had limitations; additional analysis in an alternative cohort would further verify the performance of the MSRC test. Nevertheless, the test, previously validated for ACR50, now has been validated using EULAR good response in a treat-to-target setting.

REFERENCES:

[1] Schipper LG et al, Time to achieve remission determines time to be in remission. Arthritis Res Ther 201

[2] Mellors T, et al. Clinical Validation of a Blood-Based Predictive Test for Stratification of Response to Tumor Necrosis Factor Inhibitor Therapies in Rheumatoid Arthritis Patients. Network and Systems Medicine 2020

[3] Tweehuysen $L$ et al. Predictive value of ex-vivo drug-inhibited cytokine production for clinical response to biologic DMARD therapy in rheumatoid arthritis. Clin Exp Rheumatol 2019

Disclosure of Interests: Lixia Zhang Shareholder of: Scipher Medicine Corporation, Employee of: Scipher Medicine Corporation, Celeste van der Tog: None declared, Alfons den Broeder Consultant of: Abbvie, Amgen, Cellgene, Roche, Biogen, Lilly, Novartis, Celltrion Sanofi, Gilead., Grant/research support from: Abbvie, Amgen, Cellgene, Roche, Biogen, Lilly, Novartis, Celltrion Sanofi, Gilead., Ted Mellors Shareholder of: Scipher Medicine Corporation, Employee of: Scipher Medicine Corporation, Erin Connolly-Strong Shareholder of: Scipher Medicine Corporation, Employee of: Scipher Medicine Corporation, Johanna Withers Shareholder of: Scipher Medicine Corporation, Employee of: Scipher Medicine Corporation, Alex Jones Shareholder of: Scipher Medicine Corporation, Employee of: Scipher Medicine Corporation, Viatcheslav Akmaev Shareholder of: Scipher Medicine Corporation, Employee of: Scipher Medicine Corporation DOI: 10.1136/annrheumdis-2021-eular.3396

\section{POS0493 \\ TRIPLE-POSITIVITY AND ANTINUCLEAR ANTIBODIES, INSIGHTS ON DISEASE ACTIVITY: A RETROSPECTIVE COHORT STUDY OF COLOMBIAN RA PATIENTS}

K. Maldonado-Cañón ${ }^{1,2}$, D. V. Verano Castillo ${ }^{1}$, H. F. Arenas Torrado ${ }^{1}$, P. Coral Alvarado $^{2,3}$, P. A. Mendez Patarroyo ${ }^{2,3}$, G. Quintana Lopez ${ }^{2,3,4}$ on behalf of Reumavance Research Group. ${ }^{1}$ School of Medicine - National University of Colombia, Reumavance Research Group, Bogota, Colombia; ${ }^{2}$ Fundacion Santa Fe de Bogota University Hospital, Reumavance Research Group. Internal Medicine Department., Bogotá, Colombia; ${ }^{3}$ School of Medicine - Universidad de Los Andes, Reumavance research group. Internal Medicine Department, Bogota, Colombia; ${ }^{4}$ School of Medicine - National University of Colombia, Reumavance research group. Internal Medicine Department., Bogota, Colombia

Background: Rheumatoid arthritis (RA) is a chronic autoimmune inflammatory disease characterized by cartilage and bone destruction, which can lead to joint dysfunction and disability. Antibodies' role as biomarkers in RA has been recently increasing: Anti-citrullinated protein antibodies (ACPAs) are the most specific one $(60-70 \%$ of cases); whereas rheumatoid factor (RF) is seen in nearly $70 \%$ of cases, however, it is less specific than ACPA for RA diagnosis'. ACPA/RF positivity is related to a more severe phenotype and a rapid progression to clinically apparent RA $A^{\mathrm{ii}}$. Other biomarkers are Antinuclear Antibodies (ANAs), which have been related to a worse response to bDMARD treatment $\mathrm{tiii}^{\mathrm{ii}}$.

iNishimura K, Sugiyama D, Kogata Y, Tsuji G, Nakazawa T, Kawano S, et al. Meta-analysis: Diagnostic accuracy of anti-cyclic citrullinated peptide antibody and rheumatoid factor for rheumatoid arthritis. Vol. 146, Annals of Internal Medicine. American College of Physicians; 2007. p. 797-808

iiLingampalli N, Sokolove J, Lahey LJ, et al. Combination of anti-citrullinated protein antibodies and rheumatoid factor is associated with increased systemic inflammatory mediators and more rapid progression from preclinical to clinical rheumatoid arthritis. Clin Immunol. 2018;195:119-126.

iiilshikawa Y, Hashimoto M, Ito H, Tanaka M, Yukawa N, Fujii T, et al. Anti-nuclear antibody development is associated with poor treatment response to biological disease-modifying anti-rheumatic drugs in patients with rheumatoid arthritis. Semin Arthritis Rheum. 2019;49(2):204-10.

Objectives: Our aim was to compare in terms of mean differences the disease activity according to the presence of RF, ACPA, and ANA in an outpatient clinic-based cohort of Colombian RA patients.

Methods: We conducted a retrospective cohort study with clinical-epidemiological data obtained from May 2013 to Feb. 2020 of patients with RA diagnosis based on the 2010 ACR/EULAR classification criteria. The patients were stratified into eight subgroups according to their autoantibody status. Disease activity, assessed by the DAS28-ESR, was recorded at baseline and after $3, \approx 12, \approx$ 24 , and $\approx 36(+/-3)$ months. Mean DAS28-ESR differences were calculated by applying the Wilcoxon non-parametric rank test for two independent samples.

Results: Data of 384 patients who all completed 36 months of follow-up, from an ongoing cohort of $\approx 1100$ patients, were included in the analysis. On our primarily female $(n=294,76,8 \%)$ population, $\mathrm{RF}^{+} / \mathrm{ACPA}^{+} / \mathrm{ANA}^{+}$subgroup was the most prevalent $(n=183 ; 47,8 \%)$; interestingly, it was the one with the highest disease activity at baseline. After three months, all showed disease activity reduction; however, when completing follow-up, triple-positive, triple-negative and ANA-positive patients did not reach remission. Statistically significant mean differences were displayed when comparing overall and baseline mean DAS28ESR scores for $\mathrm{ANA}^{+}$vs $\mathrm{ANA}^{-}$patients, as shown in table 1.

Table 1. Disease activity mean differences when comparing $\mathrm{ANA}^{+}$vs ANA $^{-}$patients

\begin{tabular}{|c|c|c|c|c|}
\hline & $\mathrm{ANA}^{+}(n=218)$ & ANA $^{-}(n=165)$ & Mean difference & $p$ value \\
\hline Baseline & 4,05 & 3,62 & 0,43 & 0,014 \\
\hline 3 & 3,32 & 3,14 & 0,18 & 0,396 \\
\hline 12 & 3,13 & 2,89 & 0,24 & 0,059 \\
\hline 24 & 2,80 & 2,68 & 0,11 & 0,563 \\
\hline 36 & 2,80 & 2,58 & 0,22 & 0,098 \\
\hline Overall & 3,22 & 2,98 & 0,24 & 0,002 \\
\hline
\end{tabular}

Conclusion: In our study population, triple-positive and $\mathrm{ACPA}^{+} / \mathrm{ANA}^{+}$patients showed higher disease activity at baseline and on average during the follow-up period; furthermore, ANA positivity was shown to be conditional on a significant difference for higher disease activity. RF and ACPA positive have long since been described as determinants for disease activity; nonetheless, our research provides insights for the consideration of ANA titers as a novel addition that enables the preamble of triple-positivity as something to be acknowledged. Caution must be applied when interpreting these results, understanding the need for this matter to be subject of future research with greater sample size, and taking into account other potentially confounder variables.



Figure 1. Mean disease activity for each stratum

Disclosure of Interests: None declared DOI: 10.1136/annrheumdis-2021-eular.3443

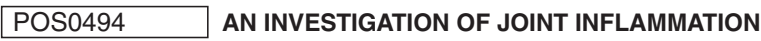 DEFINED BY COMPREHENSIVE ULTRASOUND ASSESSMENT AND PAIN SENSITISATION IN PATIENTS WITH ACTIVE RA}

K. Chaabo ${ }^{1}$, E. Chan ${ }^{2}$, T. Garrood ${ }^{2}$, Z. Rutter-Locher ${ }^{2}$, A. Vincent ${ }^{2}$, J. Galloway ${ }^{3,4}$, S. Norton ${ }^{5}$, B. Kirkham ${ }^{2}$. ${ }^{1}$ St George's Hospital, Rheumatology Department, London, United Kingdom; ${ }^{2}$ Guy's Hospital, Rheumatology Department, London, United Kingdom; ${ }^{3}$ King's College Hospital, Rheumatology Department, London, United Kingdom; ${ }^{4}$ King's College London, Rheumatology, London, United Kingdom; ${ }^{5}$ King's College London, Psychology and Inflammation Biology, London, United Kingdom

Background: Treat-to-target strategies have improved outcomes in patients with RA. Targets based on clinical assessments of tender (TJC) and swollen joints (SJC) were developed when most patients had active inflammatory disease. It is now recognised some patients have pain sensitisation often termed fibromyalgia (FM), making clinical assessment of inflammatory disease more complex. An indicator of pain sensitisation is the difference between TJC and SJC, an observation we described in a pilot study (1) 